\title{
O Ensino de Enfermagem Psiquiátrica /Saúde Mental: avanços, limites e desafios ${ }^{1}$
}

Maria Conceição Bernardo de Mello e Souza²

\begin{abstract}
O estudo teve como objetivos analisar como ocorre o ensino de Enfermagem Psiquiátrica/ Saúde Mental nos cursos públicos de enfermagem existentes no estado de São Paulo e investigar e analisar a prática pedagógica de professores responsáveis por disciplinas da área. Foram realizadas entrevistas com 12 professores, cuja verificação deu-se através da análise temática. Trata-se de pesquisa qualitativa. Resultados evidenciaram que os professores, em sua maioria, desconhecem o Projeto Político Pedagógico dos cursos de graduação em que estão inseridos; método de ensino predominante tradicional, com desejo de mudanças para uso de metodologias ativas; conteúdos de ensino prioritariamente com enfoque biologicista; apontam também desvalorização da profissão de professor. Apesar de se perceber desejo de avanços por parte desses profissionais nota-se pouco investimento na formação pedagógica dos mesmos.
\end{abstract}

Descritores: Ensino; Saúde Mental; Enfermagem; Educação.

\footnotetext{
${ }^{1}$ Artigo extraído da Tese de Livre docência "O Ensino de Enfermagem Psiquiátrica /Saúde Mental: avanços, limites e desafios", apresentada à Escola de Enfermagem de Ribeirão Preto, Universidade de São Paulo, Centro Colaborador da OPAS/OMS para o Desenvolvimento da Pesquisa em Enfermagem, Ribeirão Preto, SP, Brasil.

${ }^{2}$ PhD, Professor Doutor, Escola de Enfermagem de Ribeirão Preto, Universidade de São Paulo, Centro Colaborador da OPAS/OMS para o Desenvolvimento da Pesquisa em Enfermagem, Ribeirão Preto, SP, Brasil.
}

Correspondência:

Maria Conceição Bernardo de Mello e Souza

Universidade de São Paulo. Escola de Enfermagem de Ribeirão

Preto

Departamento de Enfermagem Psiquiátrica e Ciências Humanas

Av. Bandeirantes, 3900

Bairro: Monte Alegre

CEP: 14040-902, Ribeirão Preto, SP, Brasil

E-mail: consouza@eerp.usp.br 


\title{
The Psychiatric Nursing/Mental Health Education: advances, limitations and challenges
}

This study aimed to examine the Psychiatric Nursing/Mental Health Education in public nursing courses in the State of São Paulo, Brazil, and investigate and analyze the educational practice of professors responsible for the disciplines in the area. Interviews were conducted with twelve professors, whose verification took place through thematic analysis. This is a qualitative research. Results show that the professors are, mostly, unaware of the Pedagogical Political Project of the undergraduate courses in which they are inserted, the teaching method is predominantly traditional with desire for changes to use active methods, the teaching content has a primarily biological focus and the devaluation of the profession of professor is also present. Although we can notice a desire for advances by these professionals, we see little investment in their educational training.

Descriptors: Teaching; Mental Health; Nursing; Education.

\section{La Enseñanza de Enfermería Psiquiátrica /Salud Mental: avances, límites y desafíos}

\begin{abstract}
El estudio tuvo como objetivos analizar como ocurre la enseñanza de Enfermería Psiquiátrica/ Salud Mental en los cursos públicos de enfermería existentes en el estado de São Paulo e investigar y analizar la práctica pedagógica de maestros responsables por las disciplinas del área. Fueron realizadas entrevistas con 12 maestros, cuya verificación se dio a través del análisis temática. Se trata de investigación cualitativa. Resultados evidenciaron que los maestros, en su mayoría, desconocen el Proyecto Político Pedagógico de los cursos de graduación en la que están insertos; método de enseñanza predominante tradicional, con deseo de cambios para uso de metodologías activas; contenidos de enseño de manera prioritaria con enfoque biologicista; apuntan también desvalorización de la profesión de maestro. A pesar de percibirse deseo de avances por parte de eses profesionales notase poca inversión en la formación pedagógica de los mismos.
\end{abstract}

Descriptores: Enseñanza; Salud Mental; Enfermería; Educación.

\section{Introdução}

O ensino de Enfermagem Psiquiátrica/Saúde Mental tem sido estudado por vários pesquisadores da área no país. A maior parte das investigações procurou retratar o cotidiano do ensino de enfermagem psiquiátrica na busca por melhorar a prática profissional. No entanto, novas propostas de mudanças curriculares- Lei de Diretrizes e Bases da Educação Nacional (LDB/96) e as Diretrizes Curriculares Nacionais do Curso de Graduação em Enfermagem (DCNENF/2001), instituíram diretrizes curriculares nacionais para os Cursos de graduação 
em enfermagem, exigindo outros olhares para o ensino(1-2).

O presente estudo justifica-se por sua proposta de investigar o ensino de Enfermagem Psiquiátrica/ Saúde Mental a partir da legislação e diretrizes anteriormente citadas e de destacar a forma como o professor encontra-se inserido no processo de ensino-aprendizagem nesse contexto de mudanças.

Hoje, em qualquer área, formar profissionais com perfil adequado às necessidades sociais implica propiciar a capacidade de trabalhar em equipe, comunicar-se e ter agilidade diante das situações novas. Estas características tornam-se necessárias à formação de profissionais do futuro e não se coadunam com o modelo de ensino, segundo a concepção pedagógica tradicional, na qual o ensino se fundamenta em um tipo de currículo marcado pela passividade, submissão, falta de participação e de atitude crítica do aprendiz.

Nesta lógica, as universidades são convidadas a rever seus métodos de ensino, implantar desafios inspirados na adoção de metodologias que favoreçam o desenvolvimento do espírito crítico, da capacidade de reflexão que estimule a participação ativa dos estudantes na construção do conhecimento. São vários os autores da área da educação que colaboram para esta reflexão ${ }^{(3-4)}$.

O ensino de Enfermagem Psiquiátrica/ Saúde Mental, além de seguir as leis que regem a educação no país, segue também, alguns princípios da reforma psiquiátrica brasileira, buscando principalmente inserir os estudantes nos espaços abertos de atenção à pessoa com transtorno mental e não mantê-los exclusivamente no âmbito hospitalar ${ }^{(5-6)}$. Atualmente, a perspectiva é de que a assistência à pessoa portadora de transtorno mental apresente caráter mais humanístico e social, com vistas à construção da cidadania. Deslocar o olhar da doença para o sujeito é uma das questões que vem sendo pontuada pelos estudiosos da área de saúde mental no decorrer de vários anos ${ }^{(5-7)}$, entre outros.

Importante se faz saber de que forma o ensino na área de Saúde Mental vem lidando com essas mudanças em sua prática educacional. Como a construção dos currículos tem contribuído para atender às políticas de saúde mental? Qual tendência pedagógica prevalece no ensino? Quais os conteúdos abordados? Como ocorre a formação pedagógica dos professores? Questões que nos induzem na busca pela compreensão de como ocorre o ensino na área de Enfermagem Psiquiátrica e Saúde Mental na atualidade.

\section{Objetivos}

Analisar como ocorre o ensino de Enfermagem Psiquiátrica e Saúde Mental nos cursos públicos de graduação existentes no estado de São Paulo; investigar e analisar a prática pedagógica de professores de disciplinas da área, envolvendo os conteúdos abordados, métodos de ensino utilizados e as práticas formativas dos professores envolvidos.

\section{Metodologia}

Trata-se de estudo descritivo exploratório, de natureza qualitativa que tem justificativa no fato de possibilitar ao pesquisador observar e trabalhar com as significações, motivos, aspirações, atitudes, valores e crenças do objeto investigado ${ }^{(8)}$. A pesquisa foi realizada com professores que ministram disciplinas de enfermagem psiquiátrica e/ saúde mental nos cursos de bacharelado em enfermagem. Os dados foram coletados nos anos de 2009 e 2010. Durante o período de coleta de dados, estavam em funcioanmento 13 escolas públicas, sendo duas federais, seis estaduais e cinco municipais ${ }^{(9)}$. Apenas uma das escolas não participou desse estudo devido ao fato de o professor contatado não ter respondido ao convite em tempo hábil.

A coleta de dados foi realizada por meio de entrevista semiestruturada, seguindo um roteiro com questões abrangentes relacionadas ao perfil do professor e outras sobre o conhecimento que esses professores têm, por exemplo, da estrutura do curso; do projeto político pedagógico e os conteúdos abordados. Para o diagnóstico dos dados foi realizada Análise Temática ${ }^{(8)}$.

Quanto aos procedimentos éticos, o projeto foi aprovado pelo Comitê de Ética em Pesquisa da EERP/USP (Protocolo n0995/2009). Após aprovação foi contatado o coordenador de cada curso e solicitado uma lista com os nomes dos professores responsáveis pelas disciplinas da área de saúde mental. A escolha dos professores deu-se através de sorteio, onde o professor sorteado recebeu um convite via e-mail para participar da pesquisa, sendo um profissional de cada escola. Os participantes foram informados sobre o objetivo do estudo e assinaram o TCLE. Para preservar o anonimato, os professores foram identificados por nomes fictícios. 


\section{Análise e Discussão dos Resultados}

\section{Professores participantes deste estudo}

O grupo pesquisado foi composto por doze professores, na faixa etária de 30 a 59 anos de idade, sendo sete deles do sexo feminino e cinco do sexo masculino. Quanto à titulação, sete tinham doutorado, três deles mestrado, um apresentava especialização na área de enfermagem psiquiátrica e outro em enfermagem do trabalho. A formação dos docentes tem sua ênfase no doutorado, o que pode ser justificado pelas exigências das atuais diretrizes das universidades públicas, que têm como premissa, contratar professores que tenham no mínimo o título de doutor.

Em relação ao tempo de docência, metade dos professores estavam em atividades de docência de 03 a 13 anos e, a outra metade, de 14 a 35 anos. O tempo maior de ensino/docência pode implicar em maior experiência, contrapondo com o ingresso nas universidades de profissionais recém-formados que demonstram pouca experiência, , tanto na prática assistencial quanto na docência.

O contrato de trabalho desses docentes abrange as categorias de: professor horista (1); professor com regime de trabalho 20 horas (1) e regime de dedicação exclusiva 40 horas (10). A maioria tem contrato em Regime de Dedicação Exclusiva, o que vem ao encontro das normas das universidades públicas que favorecem o desempenho das atividades de ensino, pesquisa e extensão.

As entrevistas foram analisadas à luz da revisão da literatura. Durante o processo de análise, emergiram as seguintes categorias temáticas: $O$ professor inserido em curso de graduação em enfermagem; $A$ atuação do professor no ensino de enfermagem psiquiátrica e saúde mental e Construindo-se como docente. $\mathrm{Na}$ apresentação dos resultados estão presentes, implícita ou explicitamente, diferentes concepções de mundo, de homem, de aprendizagem, conhecimento, sociedade e cultura dos profissionais participantes. Essas diferentes concepções implicam em escolhas, tanto de abordagens pedagógicas como teóricas as quais subsidiam o ensino em saúde mental.

\section{O professor inserido em curso de graduação em enfermagem}

Nesta categoria foram trabalhadas as questões referentes às condições dos cursos onde os professores estão inseridos, no tocante à construção do Projeto Político Pedagógico, entendendo que tal construção se reflete nos eixos pedagógicos e eixos relacionados à visão sobre saúde, perfil do aluno e diretrizes do projeto.

O Projeto Político Pedagógico (PPP) é um desafio para os cursos de graduação no sentido de que, por ele, podem ser indicados novos caminhos e novas diretrizes para as escolas. Há vários caminhos para construção do PPP, os quais devem ser marcados por momentos distintos e interdependentes: o ato situacional, no qual se descreve a realidade e se desenvolve a ação pedagógica; opção pelo referencial teórico a ser seguido; quais concepções são necessárias para transformação da realidade; e operacional, ou seja, como realizar a ação(10).

A partir da LDB/96 e DCNENF/2001 são disseminadas orientações para elaboração dos PPPs em todas as instituições de ensino superior. Para atender a essa exigência legal, as escolas iniciam a discussão e construção de seus PPPs.

Cabe destacar que nas entrevistas fica explícito que nem sempre o professor teve participação na construção do projeto pedagógico:

Eu sei que existe o Projeto Pedagógico, já até tive em mãos, só que eu olhei tal...eu sei que existir ele existe[...].Só que se você perguntar para mim: ah, fale aí sobre o PPP, eu não vou conseguir falar entendeu? (Apolo).

No entanto, a participação coletiva na construção do projeto está descrita como um dos parâmetros gerais das DCNENF; assim, algumas das escolas, para responderem às diretrizes, envolvem seus docentes no processo de construção, mesmo que eles ainda não tenham clareza sobre a finalidade do PPP:

Na verdade assim, a gente construiu quando foi obrigatório pela questão da...ajudei a construir, mas, de uma forma geral, assim, eu sei o que se espera do enfermeiro, mas se você perguntar detalhadamente eu não saberia responder (Atena).

A construção, implementação e concretização de um projeto pedagógico, não se constitui tarefa fácil nem rápida; ao contrário, exige tempo e compreensão para a necessidade de mudanças e, principalmente, disposição para o rompimento com práticas já sedimentadas nas ações pedagógicas ${ }^{(10)}$.

Em relação ao perfil profissional desejado para os estudantes, as DCNENF enfatizam a formação de profissional generalista, atento às questões humanísticas, crítico e reflexivo( ${ }^{(2)}$. Além do contexto da reforma educacional, é necessário considerar também o Movimento da Reforma Sanitária, culminando com a consolidação do SUS, em 1988, impulsionando para um novo modelo assistencial de saúde que demanda 
formação de profissionais capazes de reconhecer a amplitude necessária de atuação, objetivando um atendimento às necessidades sociais(11).

Os Cursos de Enfermagem investigados neste estudo, com propósito de atenderem às DCENF, iniciam mudanças em seus currículos e propõem, em seus PPPs, a formação de um profissional generalista:

(...) ele é voltado para formação do enfermeiro generalista que possa atuar na rede hospitalar, mas, sobretudo, na saúde coletiva (Dionísio).

É enfermeiro generalista, com uma visão crítica da sociedade (...)está embasando nosso projeto (Atena).

Em relação às diretrizes e/ou bases norteadoras que regem os projetos pedagógicos dos cursos investigados, existem aspectos que dizem respeito à visão de saúde/cuidado em saúde e aos eixos pedagógicos do curso, explicitados em sua estrutura curricular.

Alguns dos participantes citam as diretrizes que Ihes são mais significativas ou aquelas mais enfocadas em cada curso em particular, muito embora todas as citadas estejam descritas nas DCNENF:

...É tem eixo, o eixo da Atenção Primária, tem outro eixo que é das Competências, o referencial das competências, o eixo também, deixo ver...Interdisciplinaridade (Afrodite).

Princípios do SUS, toda diretriz nossa é baseada neles, a ideia é formar profissionais para o trabalho no SUS (Hércules).

Em relação aos eixos pedagógicos que norteiam o projeto, segundo os relatos dos professores, as opções consideraram as atuais exigências para o ensino de graduação em enfermagem e as demandas advindas do mundo do trabalho em saúde:

É a principal diretriz talvez seja o ensino através de metodologias ativas. Nós trabalhamos com a ideia da competência do aluno, do trabalho por competência através das metodologias ativas, toda nossa prática, todo nosso projeto, ele busca que o aluno entre em contato com a prática e com as competências do futuro profissional desde o primeiro ano (Hércules).

As metodologias ativas, embasadas na concepção pedagógica crítico-reflexiva possibilitam a efetiva participação dos sujeitos envolvidos no processo ensino aprendizagem ${ }^{(11)}$.

\section{Atuação do professor no ensino de enfermagem psiquiátrica e saúde mental}

Atualmente, as instituições de ensino superior, responsáveis por formar profissionais da área da saúde, têm sido estimuladas a reverem suas práticas pedagógicas na tentativa de aproximação com a realidade social. Assim, é percebida uma busca maior por abordagens pedagógicas progressistas de ensino-aprendizagem, as quais propiciam a formação de sujeitos críticos, reflexivos, com competências éticas, políticas e técnicas, capacitando-os para intervirem em contextos complexos ${ }^{(12)}$

Por outro lado, no ensino pautado na pedagogia tradicional, os métodos baseiam-se na exposição verbal da matéria, onde a atitude do aluno é receptiva, sem qualquer interlocução com o professor no decorrer da aula $^{(3)}$. O processo ensino-aprendizagem restringese, muitas vezes, à reprodução do conhecimento. $O$ professor "passa" os conteúdos e o aluno os retém e os repetem, sem questionamento, em uma atitude passiva, tornando-se expectador, sem a reflexão e a crítica necessárias.

Em uma das entrevistas, a fala do professor aponta como fator limitante no processo ensinoaprendizagem, além do método de ensino tradicional, a estrutura curricular por disciplinas com os conteúdos compartimentados, fragmentados e não articulados:

Ainda continua no método tradicional, aquele método tradicional assim...disciplinar... tem a disciplina e ai depois os conteúdos, eles são bem divididinhos, cada um fica com a sua aula (Afrodite).

A fragmentação do saber em campos especializados levou as universidades a subdividiremse por departamentos e, consequentemente, os cursos foram formatados com estruturas curriculares, compostas por disciplinas estanques ${ }^{(13)}$.

Em alguns depoimentos é possível apreender a intenção e o desejo dos professores em utilizar metodologias ativas, embora deparem com os limites impostos pelo sistema universitário:

(...) então, a gente queria fazer um ensino mais centrado na prática com metodologias ativas, inovadoras, mas na época nos esbarramos com a estrutura da universidade, muito centrada em disciplinas (Hera)

O uso de metodologias ativas ou qualquer outro modo de ensinar, demanda capacitação pedagógica. Entretanto, a necessidade dessa capacitação, muitas vezes, não é sentida pelos professores universitários, por acreditarem que sua formação profissional, específica da área de conhecimento, basta para serem professores.

Em sua maioria, as instituições de ensino superior analisadas neste estudo são instituições tradicionais, nas quais, historicamente, são estabelecidas relações hierárquicas, tanto no âmbito da coordenação central, como nas estruturas do ensino, influenciadas pelas relações de poder marcadas no passado.

Destacam-se os conteúdos programáticos apontados com maior frequência pelos participantes 
dessa pesquisa. Verifica-se que alguns dos conteúdos contemplados pelos professores dizem respeito às psicopatologias e ao processo saúde-doença mental, ainda com enfoque biologicista, centrado na doença:

É...sobre transtornos, sobre conhecer mais o paciente, conhecer a doença, porque na psiquiatria frisa bastante isso, é uma coisa bem presente, o cuidado, a assistência e principalmente, ... o transtorno (Afrodite).

(...) psicopatologia, a gente pega os três grandes grupos só. Transtorno Ansioso, Transtorno Depressivo e Transtorno Psicótico (Hermes).

Outros conteúdos selecionados e considerados relevantes para a área de sáude mental, pelos professores, são comunicação e relacionamento interpessoal, os quais tidos como instrumentos básicos para o cuidado:

É a primeira disciplina que é só teórica, não tem laboratório e nem estágio, então é onde eles aprendem os instrumentos do cuidado de enfermagem psiquiátrica, os instrumentos básicos, comunicação, relacionamento interpessoal... (Apolo).

Em relação ao conteúdo sobre Políticas de Saúde Mental, destaca-se que, com as transformações que vêm ocorrendo no Brasil, e com olhar mais atento para assistência extramuros em serviços abertos, os professores têm repensado o conteúdo de suas disciplinas e cenários de prática para desenvolvimento de atividades junto aos estudantes.

(...)Política de Saúde Mental, toda a parte histórica... Reforma Psiquiátrica, até chegar hoje no novo modelo. A rede, os novos serviços, a clínica (...) (Hera).

Até a década de 90 , a ação de enfermagem era realizada em espaços administrativos do hospital psiquiátrico, baseada no modelo biológico. Com a Reforma Sanitária nas últimas décadas do século XX e com a consolidação do SUS e Reforma Psiquiátrica, algumas mudanças têm ocorrido, como, por exemplo, a reorientação do modelo assistencial em saúde mental(6,14).

\section{Construindo-se como docente}

Historicamente, a área de enfermagem psiquiátrica e saúde mental tem sido desvalorizada no campo da prática profissional por motivos como: o não reconhecimento profissional, a baixa remuneração e a falta de capacitação dos profissionais que atuam nesse segamento ${ }^{(15)}$.

No presente estudo, os motivos de desvalorização apontados pelo professor podem ser também reproduzidos nas instituições de ensino, como se observa a seguir:
(...) é um desafio também, porque dentro da própria faculdade, os próprios docentes...não é uma área tão valorizada, reconhecida. Então é um desafio posso dizer assim... (Artemis).

Alguns professores fazem referência às demandas da universidade e às dificuldades para atender a todas elas:

(...) mas pelo número de docentes e da própria demanda da universidade a gente não dá conta de fazer o que tem que fazer né, seria interessante se pudéssemos... (Perseu).

A divisão técnica da organização do trabalho pedagógico enfatiza uma abordagem despolitizante de prática e altera o papel do professor. A escola assume mais encargos burocráticos e administrativos em detrimento das atividades de cunho político pedagógico ${ }^{(16)}$.

O exercício da docência é sempre um processo, movimento, novo lugar, novas informações, novos sentimentos e novas interações ${ }^{(16)}$. Nesse sentido, alguns professores expressam satisfação em ser professor:

Eu adoro ser professora, eu acho que estar na enfermagem em Saúde Mental pra mim é tudo perfeito porque eu adoro essa disciplina(...) (Alceste).

(...)é uma área que eu me identifiquei desde a época da graduação e como professor também tinha como um objetivo que era dar aula na área (saúde mental). (Apolo).

Nos depoimentos permanece a ideia de que ser professor está sempre associado à área de enfermagem psiquiátrica/saúde mental, e, em momento algum, os professores fazem referência ao papel pedagógico para tal. Ser professor vai além de ser bom profissional. São necessárias competências específicas, distintas das relativas ao exercício profissional. A formação para o desempenho da docência precisa estar relacionada aos princípios que orientam a prática pedagógica ${ }^{(16)}$.

Atualmente, nas universidades públicas, tem sido enfatizada a produtividade de pesquisas, o que vem ao encontro das leis do mercado, racionalidade científica e eficiência técnica, impulsionando os professores ao trabalho individualizado, e dicotomizando teoria de prática, ensino de aprendizagem, ensino de avaliação, conteúdo de forma, e, consequentemente, inibindo as formas de se estabelecer relações de análise da própria prática, com produção de conhecimentos distante da realidade, preparando assim, indivíduos com dificuldades para leitura contextualizada do mundo(10).

Os professores entrevistados mostram o que pensam sobre o investimento prioritário em pesquisa:

(...) ás vezes eu sinto que a gente deixa um pouco de lado o papel de professor, principalmente no nível de graduação, pelas demandas que a própria universidade nos impõe (Perseu). 
Atualmente, nos concursos de ingresso e promoção nas universidades, em geral, é muito valorizada a produtividade em pesquisa. Nos departamentos, também são priorizadas as atividades de investigação, as publicações, conferindo, por vezes, um menor valor às atividades docentes ligadas ao ensino. É um risco que se corre, pois, podemos encontrar excelentes pesquisadores que não são bons professores ${ }^{(18)}$.

Os professores, de maneira geral, não fazem menção à necessidade da capacitação pedagógica para atuação no ensino:

A proposta nos primeiros dois anos é metodologias ativas né? É essa proposta, mas a gente sabe que na verdade é difícil mudar a cabeça dos professores nem todos tem formação é um grande desafio (Perseu).

"O exercício da profissão e seu domínio não ocorrem por uma transferência direta de sabedoria divina"; não se pode esperar que o professor pesquisador, ao ingressar na universidade, esteja preparado para exercer a docência. É necessário investimento na capacitação pedagógica ${ }^{(18)}$.

\section{Considerações Finais}

O estudo nos permitiu observar avanços, limites e desafios enfrentados no processo de construção dos projetos pedagógicos dos cursos, na formação pedagógica dos professores e em sua atuação na área de enfermagem psiquiátrica e/ saúde mental.

De forma geral, muitos professores desconhecem o projeto pedagógico dos cursos; às vezes são inseridos somente no sentido de responder à legislação no que diz respeito à construção coletiva. Uma barreira encontrada diz respeito à tendência em priorizar escolha de conteúdos centrados nas psicopatologias/sinais e sintomas das doenças, com menor enfoque nos conteúdos atitudinais e procedimentais. Apesar de algumas modificações que expressam aproximação a conteúdos referentes a políticas de saúde metal, o cerne das disciplinas ainda reside nas psicopatologias.

Em relação à formação docente, percebese pouco investimento das universidades nesse processo . A ideia de que quem sabe fazer, sabe ensinar, ainda está presente. Nos concursos públicos para contratação docente prioriza-se a quantidade de publicações científicas; menor valor é atribuído à formação pedagógica dos professores. Um grande desafio que emerge desta pesquisa é a compreensão de que a formação pedagógica dos professores inseridos em universidades tem sido, equivocadamente, algo presumível, algo com o que já se conta, o que requer intervenções.

\section{Referências}

1- Ministério da Educação (BR). Lei no 9394 , de dezembro de 1996. Estabelece as diretrizes e bases da educação nacional. Diário Oficial da União, Brasília (DF), 1996. 34(248), Seção 1:27. p. 833-41.

2- Ministério da Educação (BR). Conselho Nacional de Educação. Parecer CNE/CES. Diário Oficial da União 1133/2001. Diretrizes Curriculares Nacionais do Curso de Graduação em Enfermagem, 2001, 3 outubro, Seção 1E, p. 131.

3-Vasconcellos CS. Metodologia dialética em sala de aula. Rev Assoc Educ Católica. (Juiz de Fora) [Internet]. 1995 [Acesso 11 out 2014];21(83). Disponivel em: http:// www.celsovasconcellos.com.br/Textos/MDSA-AEC.pdf 4-Saviani D. Escola e democracia: teorias da educação, curvatura da vara, onze teses sobre a educação política. Campinas: Autores Associados; 2009.

5-Munari DB, Godoy MTH, Esperidião E. Ensino de enfermagem psiquiátrica/ saúde mental na Faculdade de Enfermagem da Universidade Federal de Goiás. Esc Anna Nery. 2006;10(4):684-93.

6-Aranha e Silva AL, Fonseca RMGS. Processo de trabalho em saúde mental e o campo psicossocial. Rev. Latino-Am. Enfermagem. 2005;13(3):441-9.

7-Silva MG, Silva JDF, Teixeira GAS, Silva RMO. Processo de formação da (o) enfermeira (o) na contemporaneidade: desafios e perspectivas. Texto Contexto Enferm. 2010;19(1):176-84.

8-Minayo MAS. O desafio do conhecimento: pesquisa qualitativa em saúde São Paulo/ Rio de Janeiro: Hucitec/ Abrasco; 2010.

9-Instituto Nacional de Ensino e Pesquisa. [Internet]. Brasilia: INEP; 2007. [Acesso 3 abril 2012]. Disponível em: www.portal.mec.gov.br/index,php?option.com.

10-Veiga IPA. Projeto Político Pedagógico: novas trilhas para a escola. In: Veiga IPA, Fonseca M, organizadores. As dimensões do projeto político pedagógico: novos desafios para a escola. Campinas: Papirus; 2008. p. 45-66.

11-Fernandes JD. Diretrizes Curriculares e Projetos Pedagógicos de Cursos de Graduação em Enfermagem. In: Teixeira $E$. et al., organizadores $O$ ensino de Graduação em Enfermagem no Brasil: o ontem, o hoje e o amanhã. Brasília: Instituto Nacional de Estudos e Pesquisas Educacionais Anísio Teixeira; 2006.

12-Maia JA. O currículo no ensino superior em saúde. In: Batista NA, Batista SH, organizadores. Docência em Saúde: temas e experiências. São Paulo: Editora Senac; 2004. p. 101-33. 
13-Mitre SM, Siqueira-Batista R, Girardi-de-Mendonça JM, Morais-Pinto NM, Meirelles CAB, Pinto-Porto C, et al. Metodologias ativas de ensino-aprendizagem na formação profissional em saúde: debates atuais. Ciênc Saúde Coletiva. 2008;13(supl 2):2133-44.

14- Villela JC, Maftum MA, Paes MR. O ensino de saúde mental na graduação em enfermagem: um estudo de caso. Texto Contexto Enferm. 2013;22(2):397-406.

15-Lima RVM, Pedrão LJ, Gonçalves JG, Luis MAV. Papéis, conflitos e gratificações do enfermeiro de serviços abertos de assistência psiquiátrica. Rev. Eletrônica de Enferm. [Internet]. [Acesso 2 abril 2014]. Disponível em: www.fen.ufg.br/revista/v12/n2/v12n2a19.htm.

16-Cunha MI. Inovações pedagógicas: o desafio da reconfiguração de saberes na docência universitária. São Paulo: Universidade de São Paulo, Pró-Reitoria de Graduação; setembro 2008. Cadernos de Pedagogia Universitária, 6.

17-Reibnitz KS, Prado ML. Inovação e educação em enfermagem. Florianópolis: Cidade Futura; 2006.

18-Zabalza MA. O ensino universitário: seu cenário e seus protagonistas. Porto Alegre: Artmed; 2004. 